\title{
DESIGN, FABRICATION AND TESTING OF BANANA FIBRE EXTRACTION MACHINE
}

\author{
Sachin Poudel, Sushil Chapai, Raj Kumar Subedi, \\ Tark Raj Giri, Sunil Adhikari
}

\begin{abstract}
Banana (Musa paradisiacal $L$ ) is the fourth most important crop in the world after rice, wheat and maize. Banana cultivation in Nepal is more popular like other agricultural products and has annual fibre production of about 1,977 tons. The thick, fleshy and fibrous pseudo stems that are left over after harvesting the bananas can be used to extract high quality fibre. Farmers usually throw away this whole stump because it is big and heavy and takes a long time to rot and the animals do not eat it. The cost of importing extraction machine from other country is expensive. The research and development of such machine with low cost, which ultimately provides opportunity of local entrepreneurship to farmers and helps in proper utilization of agricultural management, was felt necessary. The developed machine from this project, uses combined application of roller and a decorticator for fibre extraction. The machine can extract fibre from $1,648 \mathrm{Kg}$ of input which is about 100-160 banana pseudostem. The fibre production obtained was $54 \mathrm{Kg}$ per day with NRS. 11 operation cost per $1 \mathrm{Kg}$ of fibre. The production efficiency in comparison to available commercial machine is $180 \%$.
\end{abstract}

Keywords : Banana fibre extraction machine, Roller, Decorticator, $54 \mathrm{Kg}$ per day, Rs. 11 per $\mathrm{Kg}$.

\section{Introduction}

Natural fibre is a thread or filament obtained from a plant or animal tissues, mineral substances, or synthesized by mixing them. There are many sources of natural as well as artificial fibre in the world which are in extreme use for several purposes like clothing, rope making, mats, carpet, decorative products and other accessories. Banana trunk bark is also a common source of natural fibre. The use of the banana steam as the source of fibre has a capability to take place of convenient fibre such as cotton and silk and in recent year the commercial value of banana fibre has increased all over the world for multiple purposes of making the tea bags, car tyre and japan yen note.

\subsection{Need of Research}

Nepal is highly dependent to agricultural aspects and there it needs more development in such aspects. Most of the civilians in Nepal has occupation as farmer. Banana is one of the most popular cultivate in Terai regions and in some of the hilly regions too. Banana is high value agricultural product and major fruit in Nepal in terms of the potential growing area, production and domestic consumption. It is currently grown in 68 of Nepal's 77 districts, and the total productive area of banana plantations in 2012/2013 was 11,864 hectare (ha), with a total production of about 182,000 tones. 
Demand for bananas in Nepal currently exceeds the total national production. According to the Trade and Export Promotion Centre of the Government of Nepal, in 2011/2012 Nepal imported 27,878 tons of bananas from India to meet the domestic demand, particularly in urban and peri-urban areas.[1]

Banana do not grow from seed but from bulb rhizome, and it takes 10 to 12 months for sowing a banana bulb to harvesting the fruit. [2]

The banana flower appear in six or seven month, banana are available all around the year. Banana plants thrive in tropical region where the average temperature is $80{ }^{\circ} \mathrm{F}$ $\left(27^{\circ} \mathrm{C}\right.$ ) and yearly rain fall is in between the 78 and Design, Fabrication and Testing of Banana Fibre Extraction Machine 98 inches, and the plant also required the rich, dark and fertile soil. [3]

There is another benefit of banana cultivation, for banana fibre. After the banana fruit is collected the banana trunk is left for degradation as waste but if utilized properly, fibre can be extracted from trunk bark. Also after the extraction of the fibre from the bark the residue waste can be further used for paper manufacturing makes ease for it. [4]

\subsection{Objectives}

\subsubsection{Main Objective}

- To perform a detailed design analysis, fabrication and testing of banana fibre extraction machine.

\subsubsection{Specific Objectives}

- To analyse different possible designs and to build an easy operational banana fibre extracting machine.

To perform economical analysis of the project.

\section{Methodology}

\section{a. Desk Study}

- Literature review

- Mechanism study

- $\quad$ Feasibility study

- b. Expert Consultation

- Experts of machine design

- Experts of nettle fibre extractor

- $\quad$ Other concerned personnel

\section{c. Field Visit}

- Visit of banana garden

- Visit of similar projects

\section{d. Market Research}

- Banana production in Nepal

- Banana demand and supply

- Commercial use of fibres extracted

e. CAD Design

- $\quad$ Selection and design of fibre extraction mechanism

- Basic simulation and analysis 
- $\quad$ Selection and design of belts and chain

- Material selection

\section{f. Model Study}

- $\quad$ Solidworks design of model

- Fabrication of model

- $\quad$ Testing of model

\section{g. Result Analysis}

- Analyzing obtained data and results

- Rational decision based on result analysis

h. Design Modifications

- Appropriate modifications based on result analysis and calculations

- Modifications based on material availability

i. Prototype Fabrication

- Fabrication of frame

- Fabrication of roller sets

- Assembly of various parts

j. Prototype Testing

- $\quad$ Measurement of different necessary parameters

- Study of dynamics and kinetics

- $\quad$ Study of ergonomics

\section{k. Result Verification}

- Machine efficiency

- Fibre extracting rate

- Power input to fibre output ratio

l. Documentation

- Documentation of methodologies involved

- Documentation of prototype

- Documentation of prototype fabrication

- Documentation of other processes

m. Final Report Preparation

- Formal report preparation

- Submission to department

\section{Design}

\subsection{Determination of Speeds Required in Different Shafts}

The machine requires two set of rotational speed for a pair of rollers and for decorticator. Lowering the speed of rollers results in better compression. By literature review and expert consultation, it was decided to keep the roller tangential velocity as $0.3-0.4 \mathrm{~m} / \mathrm{s}$, above which scratching of decorticator becomes inefficient. In order to reach this speed from the driver we need series of speed reduction. [5] 


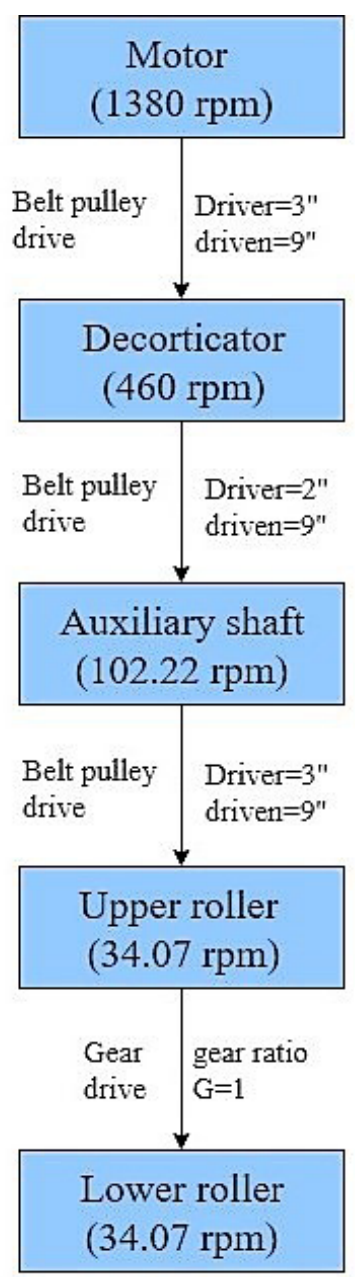

Figure 1: Block Diagram of Power Transmission

\subsection{Determination of Driver (Motor) Power}

\section{Roller:}

Tangential force, $\mathrm{Ft}=10 \mathrm{Kgf}=98.1 \mathrm{~N}$

Radial force, $\mathrm{Fr}=100 \mathrm{Kgf}=981 \mathrm{~N}$

Roller speed, $\mathrm{Nr}=34.07 \mathrm{rpm}=3.56 \mathrm{rad} / \mathrm{s}$

For each roller, $\mathrm{P}=\mathrm{T} \times \mathrm{Nr}=35 \mathrm{Watt}$

For pair of roller, $\operatorname{Pr}=2 \times \mathrm{P}=2 \times 35$

$=70$ Watt

2. Decorticator:

Impact force, $\mathrm{Fi}=5 \mathrm{Kgf}$ Speed, $\mathrm{Nd}=460 \mathrm{rpm}=48.17 \mathrm{rad} / \mathrm{s} \mathrm{Pd}=\mathrm{T} \times \mathrm{Nd}_{\mathrm{d}}=236 \mathrm{Watt}$ Hence total power required, $\mathrm{P}=\mathrm{Pr}+\mathrm{Pd}=306 \mathrm{Watt}$

\section{Fabrication and Assembly}

Before fabrication, all the components, assembly and sub-assembly were modeled in CAD software "SOLIDWORKS 2016" along with motion study, standard design and 
selection process were followed for major components like: shafts, bearings, pulley, gear etc. After the search for the workshop, it was decided to fabricate the machine in "Power Tech Nepal", Patan Industrial Estate. Fabrication of machine took about 20 days.

Equipments Used: Lathe machine, Power drill, Arc cutter, Angle grinder, Arc welding, Bench grinder, Rolling machine, Press, Meter saw, Pliers, Screw drivers, Spanners, Bench vice, Wrench, Spray painter, Hammer.

\subsection{Major Components}

\subsubsection{Frame}

The frame is made up of $25 \times 40 \mathrm{~mm}$ square pipe of thickness $2 \mathrm{~mm}$. The material choosen for the frame is mild steel. It has welded permanent joint. The weight of frame is $20 \mathrm{Kg}$.

Function: Assembles all other machine components.

Bears loads of machine components and provides rigid housing.

\subsection{Roller}

The rollers are also made up of mild steel metal plate of $8 \mathrm{~mm}$ thickness. It is made by rolling plates into hollow cylindrical shape with both external diameter and length of $200 \mathrm{~mm}$. The surface of the roller is knurled to increase friction between banana bark and roller surface for proper grip.

Function: Compress the banana bark, removes water.

\subsection{Decorticator}

The decorticator is made by welding metal stringers of $25 \times 5 \mathrm{~mm}$ over two plates. The diameter of decorticator is $200 \mathrm{~mm}$ and its length is also $200 \mathrm{~mm}$. Also a shaft of $25 \mathrm{~mm}$ is welded concentric to the decorticator.

Function: Peels out bark residues and leaves fibre. Major responsibility for fibre extraction.

\section{Design, Fabrication and Testing of Banana Fibre Extraction Machine}

\subsubsection{Motor}

A single phase motor of 1HP power with 6.8 Ampere and $1380 \mathrm{rpm}$ is used. The power factor of the motor is 0.68 with efficiency of $68 \%$.

Function: Drives machine system. Provides power for bark compression.

\subsubsection{Auxiliary Shaft}

The mild steel shaft $30 \mathrm{~mm}$ diameter and $390 \mathrm{~mm}$ length is used as idler shaft. Function: Reduces speed at rollers. Increases compression torque in rollers.

\subsubsection{Pulley}

Six pulley in total will be used. one pulley of 2 inch, two pulley of 3 inch and three pulley 
of 10 inch will be used. The pulley were bought from the market.

Function: Transmit rotational power. Assist in speed reduction.

\subsubsection{V-Belts}

The V-belts A1143, A1245 and A1270 are used. Function: Transmits power form motor to shafts. Transmit power between shaft.

\subsubsection{Bearing}

The bearing of UCP -206 four in number and UCP -205 four in number were used. The UCP has advantage in case shaft are not perfectly aligned.

Function: Platform for shaft to friction free rotation.

\subsubsection{Gears}

A pair of spur gears of gear ratio one and pitch circle diameter $203 \mathrm{~mm}$ and face width 17 $\mathrm{mm}$ is used. The module of gear is 2.54 with pressure angle 20 degree. The gear material is cast-iron. The power between two roller is transmitted with the help of gear.

Function: Transmits power form upper to lower roller. Enable same speed but opposite direction.

\subsubsection{Fastner Nut-Bolts}

The M 8, M 10 and M12 bolts and paired nut were used. Two washers for a pair of nut bolts were used.

Function: Fastens bearings and motors to the frame.

\subsubsection{Guides and Covers}

Three guides and covers made up of sheet metals of thickness $3 \mathrm{~mm}$ are used in the machine. Feed guide is kept at the front part. Roller-decorticator guide is kept in between of rollers and decorticator. Bottom guide is kept just below the roller and decorticator.

\section{Testing and Result Analysis}

The testing was performed to compare the actual performance with the expected outcome. Based on the deviation of actual parameters from expected parameters, design modification is necessary. Following parameters were studied in our testing. 


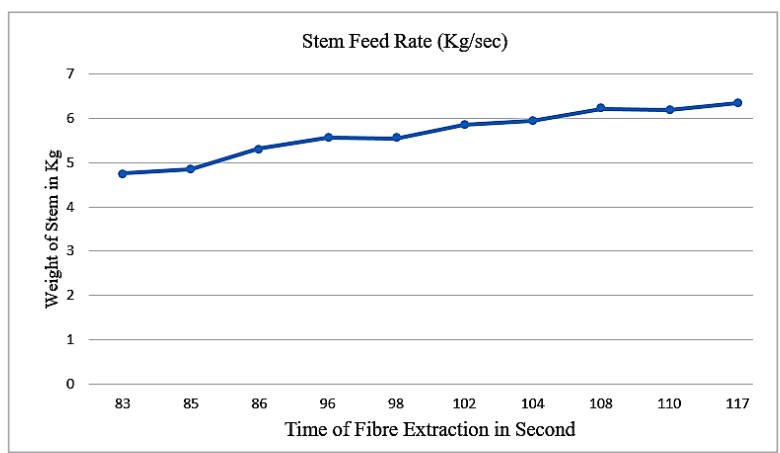

Figure 2: Feed Rate Vs. Weight and Time

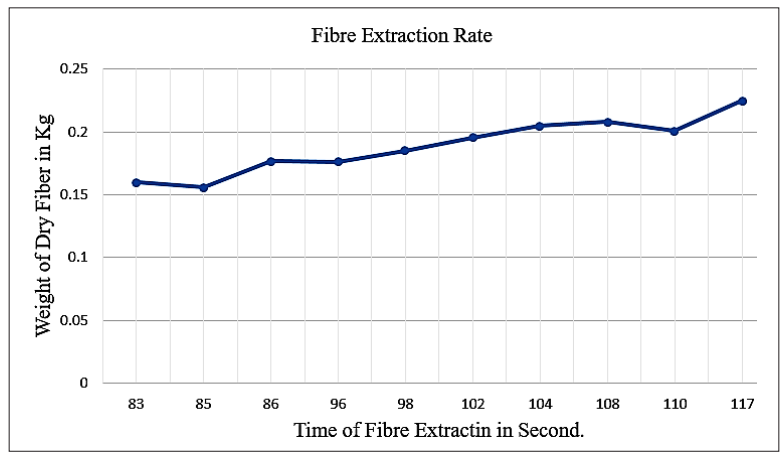

Figure 3: Fibre Production Rate by Weight and Time

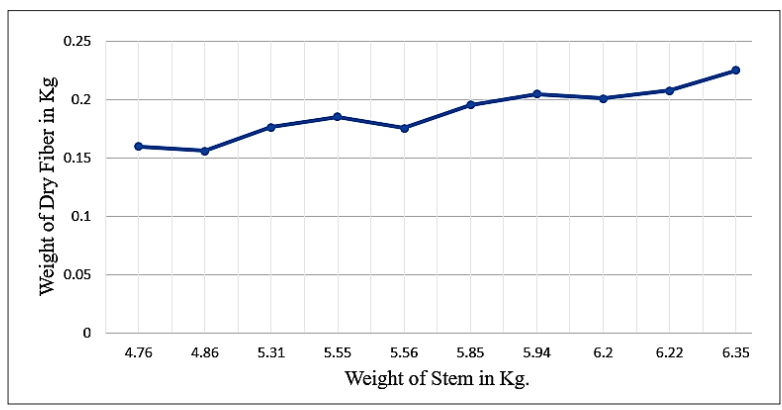

Figure 4: Fibre by Weight per Unit Weight of Stem

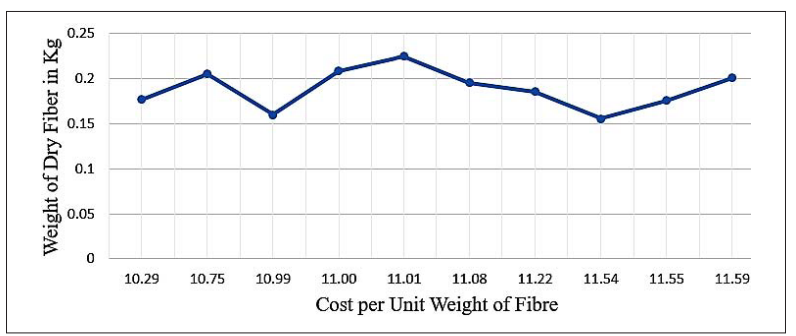

Figure 5: Cost of Production per Kg of Dry Fibre 


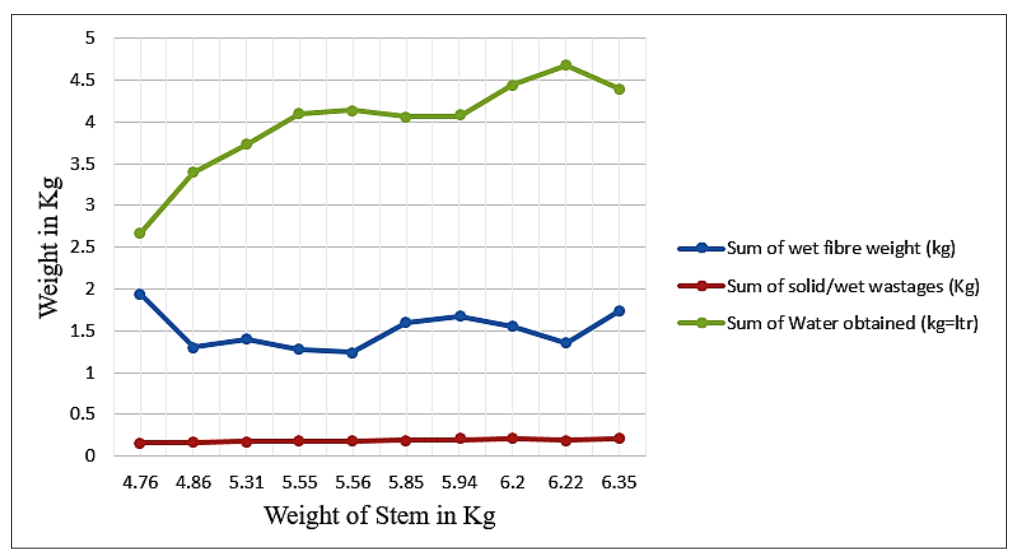

Figure 6: By-Products Weight Versus Stem Weight

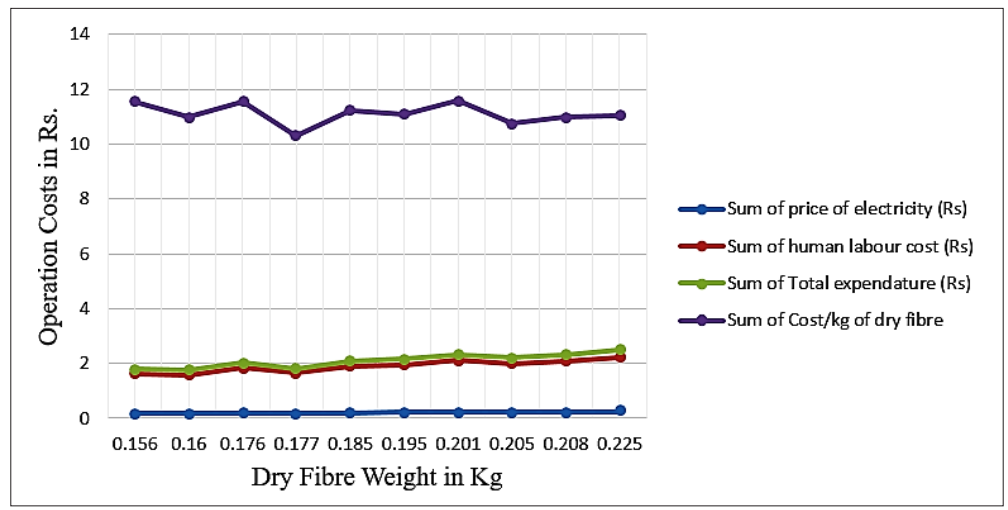

Figure 7: Operational Costs Per Fibre Produced

\section{Conclusion and Recommendations}

\subsection{Features of Prototype Machine}

1 The machine has total dimension of $500 \times 500 \times 965 \mathrm{~mm}$ cube with the total weight of $100 \mathrm{~kg}$.

2 The roller gap in the machine is $0.5 \mathrm{~mm}$.

3 Feed guide is used at the entrance of the machine.

4 The banana bark is passed through single stage of rollers followed by decorticator.

5 A curled surface guide is used along the periphery of decorticator for high efficiency.

6 There is a passage for the removal of water.

7 Rectangular blades are used in the decorticator.

8 The efficiency of the machine is high when bark with approximately $1 \mathrm{~m}$ length is fed. 


\subsection{Conclusions}

1 The machine has an average capacity of producing $1.507 \mathrm{~kg}$ of wet fibre per $\mathrm{Kg}$ of banana pseudostem, along with residue wastage and water content collectively $4.15 \mathrm{~kg}$ in 99 second. Average weight of the dry fibre was found to be $0.0334 \mathrm{~kg}$,

2 The machine has the production efficiency of $54 \mathrm{Kg}$ per day with operational cost Rs.11.07 per kg of fibre.

3 The suitable feed rate is approximately one bark in every 10 second.

4 The vibration and noise generated in extraction process is very less.

5 Once the bark is rolled or decorticated, it can't be subjected for second feed.

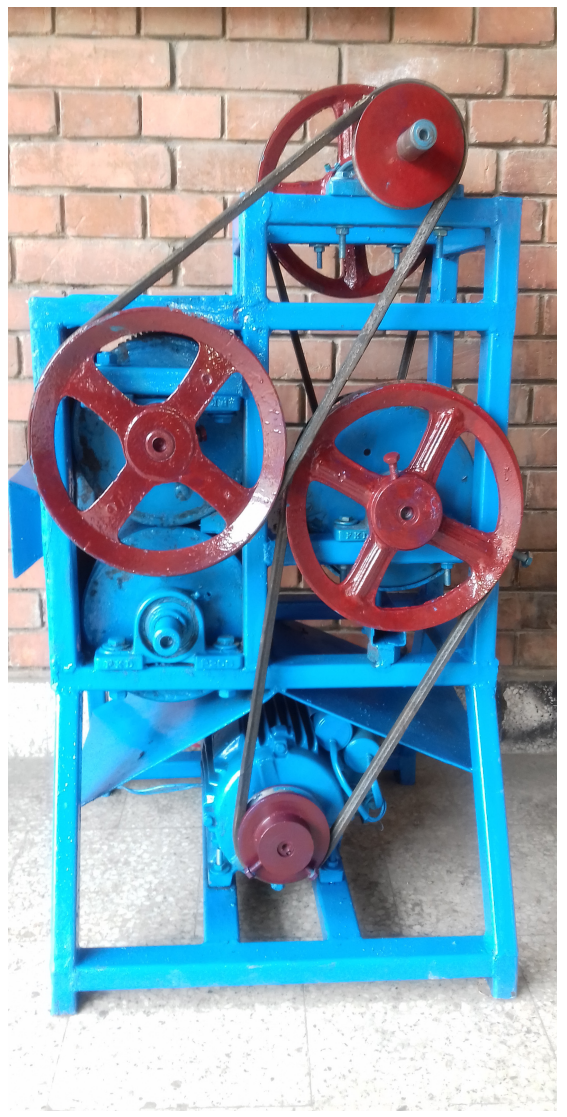

\subsection{Recommendations}

1 Increment of roller surface friction for more effective grip.

2 Use of adjustable roller gap mechanism (spring or nut-bolt tightening).

3 Increment of roller width to prevent middle stuck.

4 Chain-sprocket drive for roller at low speed to make continuous power transmission.

5 Reduction of roller speed for effective decortication.

6 Proper study in decorticator profile, number of hitting blades.

\section{Acknowledgments}

We are very thankful to our supervisor Er. Sunil Adhikari for his immense support. We express our deepest gratefulness to Institute for Social and Environmental Transition -Nepal (ISET-N) for the supportive consideration of this project for the worth of financial aid and thus awarding the project with Abhiskar Fellowship (2018).

[1] Expanding commercial banana production in nepal. http://www.icimod.org/?q=19770.

[2] AG Kulkarni, KG Satyanarayana, PK Rohatgi, and Kalyani Vijayan. Mechanical properties of banana fibres (musa sepientum). Journal of materials science, 18(8):2290-2296, 1983.

[3] P Shashi Shankar, Dr K Thirupathi Reddy, and V ChandraSekhar. Mechanical performance and analysis of banana fiber reinforced epoxy composites. International journal of recent Trends in Mechanical Engineering, 1:1-10, 2013.

[4] Easy way to extract banana fibre. https://www. thehindu.com/thehindu/seta/2003/01/ 23/ stories/2003012300180300.htm, JULY 09, 2012.

[5] Joseph Edward Shigley. Shigley's mechanical engineering design. Tata McGraw-Hill Education, 2011. 